\title{
Leer texto literario en la escuela: una experiencia placentera para encontrarse consigo mismo*
}

Fecha de recepción: 04 de diciembre de 2015

Fecha de aprobación: 04 de marzo de 2016

\section{Resumen}

El escrito relata los resultados de la experiencia de un proceso de investigación en la Maestría de Literatura dentro de la línea de investigación Creación y Pedagogía de la UPTC en el año 2013. Su objetivo principal fue acercar a los jóvenes de grado décimo de la Institución Educativa Silvino Rodríguez hacia la lectura literaria placentera a través de la aplicación de estrategias para la iniciación literaria, buscando promover la motivación, el gusto, el enamoramiento de nuevas formas de pensar, de mirar y de crear a través del disfrute estético que produce la lectura. El diseño metodológico se enmarcó dentro de una investigación cualitativa de tipo descriptiva-explicativa, con un diseño cuasi experimental. Los referentes teóricos se sustentan en autores como Louise Rosenblatt, Michele Petit, Teresa Colomer, Jorge Larrosa y María Helena Robledo entre otros. Los datos fueron recolectados a través de ejercicios con los estudiantes, profesores y padres de familia. Se hizo un análisis de las categorías halladas en la prueba de encuestas, una evaluación de los resultados, junto con las estrategias utilizadas, y finalmente se presentan unas conclusiones de la investigación.

Palabras clave: lectura, literatura, estrategias, mediación, lenguaje.

Citar: Bolívar Calixto, C.P., \& Gordo Contreras, A. (julio-diciembre de 2016). Leer texto literario en la escuela: una experiencia placentera para encontrarse consigo mismo. La Palabra, (29), 199-211.

\section{Claudia Patricia \\ Bolívar Calixto}

Universidad Pedagógica y Tecnológica de Colombia. Licenciada en Idiomas. Especialista en Literatura y Semiótica - Investigación Docente. Magíster en Literatura. Investigadora Grupo de Investigación Creación y Pedagogía. Docente de Lengua Castellana en la I.E. Silvino Rodríguez.claudiapbolivarc@gmail.com

\section{Aurora Gordo Contreras}

Universidad Pedagógica y Tecnológica de Colombia. Licenciada en Artes Plásticas. Especialista en Literatura y Semiótica. Magíster en Educación. Coordinadora Grupo de Investigación Creación y Pedagogía. Docente Asociada de Planta. Escuela de Artes Universidad Pedagógica y Tecnológica de Colombia, Tunja. auroragordoc@gmail.com

* Este artículo de investigación surge del proyecto de investigación titulado "Estrategias de iniciación, acercamiento y enamoramiento hacia el texto literario en el ámbito escolar" adscrito al Grupo de Investigación Creación y Pedagogía, y desarrollado en la Maestría en Literatura de la Universidad Pedagógica y Tecnológica de Colombia 


\title{
la palabra
}

\section{Reading Literature in School: a Pleasant Experience for Finding Oneself}

\begin{abstract}
This article presents the results of a research process in the Masters of Literature, UPTC, in the line of Creation and Pedagogy, in the year 2013. Its principal objective was to engage tenth graders of Institución Educativa Silvino Rodríguez in pleasant literary reading, through strategies of literary initiation which sought to promote motivation, experience and seduction into new ways of thinking, seeing, and creating through the aesthetic pleasure produced by reading. This was a qualitative, descriptive-explanatory research proyect, with quasi-experimental design; which used authors such as Louise Rosenblatt, Michele Petit, Teresa Colomer, Jorge Larrosa, María Helena Robledo, as theoretical referents. The data was collected through exercises with students, teachers and parents. Categories were analyzed on the basis of surveys and and evaluation of results and strategies. Finally the conclusions are presented.
\end{abstract}

Keywords: Reading, literature, strategies, mediation, language.

\section{Lire des textes littéraires au Lycée : une expérience de plaisir pour se retrouver avec soi-même}

\section{Résumé}

Cet article met en évidence les résultats d'une expérience au sein du laboratoire de recherche de Création et Pédagogie du Master de Lettres de 1'UPTC en 2013. On a voulu présenter aux élèves de première du Lycée Silvino Rodríguez la lecture comme une expérience de bonheur à partir de stratégies d'initiation à la lecture, de motivation et de gout. On a voulu intéresser les élèves, à partir du plaisir esthétique éprouvé dans la lecture, à de nouvelles formes de penser, observer et créer. On a utilisé une méthodologie de recherche qualitative de type descriptive-explicative quasi expérimentale. On a utilisé comme support théorique des auteurs comme Louise Rosenblatt, Michel Petit, Teresa Colomer, Jorge Larrosa, María Helena Robledo. On a relevé les résultats à partir d'exercices réalisés avec les étudiants, les professeurs et les parents d'élèves. On a réalisé une analyse des catégories relevées dans l'épreuve des sondages, on a évalué les résultats et les stratégies utilisés et, finalement, on a présenté les conclusions de la recherche.

Mots-clés: lecture, littérature, stratégies, médiation, langage. 


\section{Preámbulo}

Los hallazgos que se presentan en el presente artículo hacen parte de una tesis en la maestría en Literatura de la Universidad Pedagógica y Tecnológica de Colombia, cuyo tema fue la lectura literaria en el aula de clase, para ello, se implementaron estrategias de promoción de lectura con estudiantes de grado décimo de una Institución Educativa de la ciudad de Tunja, orientadas a que los estudiantes se acerquen a este tipo de lecturas y logren apropiarse y enamorarse de los textos, recursos y posibilidades de esta práctica académica, estética $\mathrm{y}$ emocional.

En Colombia, distintas investigaciones señalan dificultades en el proceso de aprendizaje y producción e interpretación de la lectura literaria, trabajos de distintas universidades como la misma UPTC, la Universidad Nacional, la Distrital, así lo demuestran. Estudios realizados evidencian el bajo nivel de comprensión de lectura de los estudiantes latinoamericanos (Reyner, 2005). Borrero (2012) se pregunta, ¿de qué manera nuestras actuales prácticas literarias están respondiendo al mundo en que vivimos? Y afirma,

A pesar de la diversidad de propuestas teóricas y prácticas existentes, la literatura que se practica en las academias, en la industria literaria, en los concursos literarios y las becas hoy en día parece mantenerse a favor de una definición de la literatura como un arte de la escritura fabricado en lenguaje verbal que toma la forma de obras consideradas literarias. El concepto de obra exige un cierto concepto de lo que es un autor, qué es "hacer literatura" y qué es "trabajar con literatura" y para qué. [...] ¿Qué prácticas literarias se desprenden de este concepto de literatura? (pp. 57-58).

En el Colegio en donde se desarrolló el estudio, se evidenciaron diferentes problemáticas como: prácticas poco significativas de lectura, dificultades de expresión oral, desconocimiento de las habilidades necesarias para leer y escribir, dispersión, falta de interacción entre el texto y el sujeto que lo aborda. Esta panorámica que incide en la comprensión de textos en los estudiantes, generó la pregunta de ¿cómo motivar, enamorar y orientar a los estudiantes para que se acerquen a la lectura literaria?

Por lo tanto, se hizo necesario establecer estrategias didácticas relacionadas con la lectura y la escritura para aportar al desarrollo de las competencias lectoras en los estudiantes. En consecuencia, se realizó un ras- treo de autores que integraran teorías y conceptos de literatura, lectura literaria, literatura juvenil, relación lector-texto y la lectura como experiencia, Louise Rosenblatt, Jorge Larrosa, Beatriz Helena Robledo y Teresa Colomer en cuanto al papel de la escuela en los procesos lectores. Federico Altamirano (2012) afirma que la función de la didáctica de la literatura no es solo enseñar, sino también contagiar; admira a Borges porque puso en práctica una creencia pedagógica a la hora de abordar la educación literaria, donde concebía la literatura como un hecho estético que solo podría apreciarse a través de la sensibilidad o el sentimiento estético.

Lo cierto es que cada concepto, cada reflexión y cada libro utilizado generaron un entramado dinámico para la propuesta y el estudio. El diálogo con estos autores permitió reflexionar acerca de ¿qué tenemos?, ¿qué sabemos?, ¿qué conocemos?, ¿qué necesitamos para motivar y enamorar a los estudiantes de la lectura literaria? De igual manera, analizar el papel de la lectura en la realidad social, así como nuestro papel como docentes y mediadores de literatura. También, apropiarse del planteamiento de Jorge Larrosa, referido a que el texto no puede ser un objeto para analizar, sino que debe ser una voz para escuchar. Para concluir, que el tipo de relación estudiante-maestro influye en el interés y el com- 
portamiento del discente, la motivación con la lectura y una comprensión lectora.

La experiencia con un texto no solo se refiere al acto de leer, sino que está relacionada con la estética (un estilo) y la ética (modo de conducirse), es individual y ayuda a la maduración del sujeto, enseña a vivir humanamente y es diferente al experimento, porque solo se produce cuando hay condiciones adecuadas en tiempo, lugar, espacio y relación texto lector, solo entonces la lectura se convierte en experiencia (Larrosa, 2003). En consecuencia, en todos los encuentros se insistió sobre la importancia de cada experiencia como forma de vida, como forma de vivir y de sostener la vida.

Para suscitar esta experiencia, se escogió la literatura infantil y juvenil como un espacio-oportunidad diferente, que se le ofrece al niño y al joven para que acceda al mundo literario dentro del ámbito escolar. En palabras de Robledo (2013),

La literatura infantil tiene una función formadora por excelencia: no didáctica ni pedagógica, sino formadora: La experiencia estética que genera la literatura literaria cultiva en los niños la capacidad de imaginar mundos posibles o de comprender su propio mundo a partir de la vida de otros, como ellos, pero en el terreno de lo imaginario. Permite, además adentrarse en las sutilezas del lenguaje, en los matices que ofrecen claves para ver los claro oscuros de la realidad. La literatura les facilita palabras para nombrar su mundo caótico e incomprensible. Los niños son plenos, pero el mundo es de los adultos. Y por esto, entregarles la literatura como una posibilidad de libertad, de trasgresión del mundo a veces incomprensible del adulto, es otorgarles las herramientas para nombrar $\mathrm{y}$ comprender su mundo y el de los otros, para crecer en el ejercicio del derecho a la palabra, al pensamiento y a la voz propias (p. 10).

De la misma manera, lo afirma Cervera (1989), “[...] la literatura infantil es la respuesta a las necesidades del niño. Este es su espacio en el panorama cultural" (p. 164).

\section{Proceso de desarrollo}

Este trabajo investigativo se enmarcó dentro de una investigación de tipo descriptiva-explicativa, con un diseño cuasi-experimental, en cuanto este enfoque investigativo carece de control experimental, y no puede controlar todas las variables de estudio. El juego de mediaciones y estrategias se logra con la constante relación de la teoría con los libros leídos, se combinan maneras de ser y concebir la literatura, buscando el enamoramiento hacia la misma.

El trabajo se desarrolló en varias etapas: la primera, relacionada con un diagnóstico sobre los hábitos de lectura en el aula de clase y fuera de ella, en donde se encontró una correlación estrecha entre la carencia de lectura, dificultades de aprendizaje y la comprensión de textos literarios. Aplicando la codificación abierta y la codificación axial para datos cualitativos, los resultados de las encuestas aplicadas se organizaron en cuatro categorías de análisis: hábito lector y mediación, actitud frente a la lectura literaria, intereses juveniles y acceso a la literatura.

En la segunda fase se realizó un acopio de información para la construcción de unos referentes teórico-conceptuales que fundamentaran la propuesta. Para ello, se abordó el concepto de literatura desde las teorías de Rosenblatt (2002), quien expresa que la obra literaria existe en el circuito vivo que se establece entre el lector y el texto, ya que el lector infunde significados intelectuales y emocionales a la configuración de símbolos verbales, y esos símbolos canalizan sus pensamientos y sentimientos. Además, se asumió la literatura como narración de vida, de libertad de pensamien- 
to y acción tanto para el escritor como para el lector. De acuerdo con Gianni Rodari (citado en Colomer, 2005), "No se enseña literatura para que todos los ciudadanos sean escritores, sino para que ninguno sea esclavo" (p. 44).

Retomando a Colomer (2005), durante siglos, la literatura ha ejercido un papel preponderante como eje central no solo de la enseñanza lingüística sino de la formación literaria y la huella que esta ha dejado en las mentes de los estudiantes en términos de representación (Suárez Gómez, 2011), placer (Flores Davis, 2010; Hauy, 2014), motivación e interés (Merino Risopatron, 2011), ajuste a los ejes de acceso al libro (McKee Irwin, 2013), contexto, escuela y uso social (San Juan Álvarez, 2011).

Bruner (1986) recuerda que las experiencias humanas se expresan a través de la participación en lo simbólico, y, por lo tanto, la vida resulta comprensible en razón a estos mismos sistemas de interpretación. Rosenblatt (2002) añade que la literatura vuelve comprensivas estas formas simbólicas, porque hacen frente y contextualizan las infinitas posibilidades de la vida, por ello, para Lince Campillo (2013) se convierte en el fluir de la vida en el texto.

De otra parte, y como función de la escuela, la literatura no solo hace parte de los aprendizajes, sino que igualmente entroniza la experiencia de la vida en el contexto y esto no solo hace lectores competentes, sino que construye la ciudadanía como uno de los muchos objetivos (Colomer, 2005) que la literatura tiene en la escuela.

Es evidente que el adolescente en la construcción de su personalidad cuenta con la literatura como experiencia, ya que ella le permite una salida emocional, a pesar de los diversos significados que pueda generar en el lector (Rosenblatt, 2002). Por consiguiente, casi siempre, el lector busca una gran variedad de satisfacciones, el disfrute de lo natural, el esplendor de lo exótico, la curiosidad por la vida, entre tantos.

Entonces, la relación entre lector-obra literaria no es llana, es compleja, por lo que la intención del texto se descubre cuando el lector devela el contenido literario y traspasa los límites del autor. En consecuencia, lo literario del texto vive cuando el lector asume, revela, ausculta, critica, interpreta y coexiste con la historia, sintiendo una des-acomodación que lo invita a la reflexión de muchos temas, al encuentro consigo mismo y a alcanzar el goce del texto.

Se puede plantear, entonces, que el proceso creativo es lo que vivimos, sentimos y experimentamos al bailar, pintar, escribir $y$, en general, en todas las manifestaciones del ser humano. Por lo tanto, en cada momento cotidiano de la vida se ve reflejada la sensibilidad e imaginación, y tenemos que valernos de nuestro potencial creativo para que dichos momentos se acoplen a cada necesidad específica.

Además de ello, es tan invaluable la noción de que la literatura es la que narra la vida, que el elemento humano jamás se puede descartar de esta narración, debido a que es en ese cruce que surge la experiencia estética, que se teje al crear con palabras, se devela y se recrea la vida. Por lo tanto, la literatura deja de ser un acto ajeno para el estudiante al implicarlo en ella, logrando, en algunos casos, que se sumerja y se vea reflejado en el vasto entramado literario que le ofrece autodescubrimiento, viajes por diversos mundos posibles llenos de: experiencias, ideologías, dolor, pasión, odio, belleza y conflictos, entre muchos otros.

Colomer (2005) sugiere fomento, intervención, mediación, familiarización, animación, para incluir y referir el tema en el ámbito escolar, teniendo como precedente en particular que la lectura compartida es la base de la formación de lectores. Tanto para Rosenblatt (2002) como para Colomer (2005), diversas prácticas escolares respaldan la idea de "compartir", como base para la formación de lectores en 
la escuela. Borrero (2012) imagina una literatura donde ubicáramos las figuras del lenguaje no para explicarlas sino, continuarlas, desenrollar hasta sus últimas consecuencias la vida sobre el lenguaje y el lenguaje sobre la vida.

En el ámbito escolar, la formación de lectores se fundamenta en la lectura compartida, sugiriendo con ello el fomento, la intervención, la mediación, la familiarización y la animación, por esta razón, diversas prácticas escolares respaldan esta idea de "compartir". Sin embargo, uno de los problemas que afronta el profesor en la enseñanza de la literatura es el de crear una situación favorable a la experiencia vital de la literatura, que implica lograr la distancia del estudiante con la preocupación académica y acercarlo al valor personal que entra en la relación estrecha vital, cercana a la experiencia de su vivir, o al vivir que lo interpela, que lo mueve o que lo hace ciudadano (Colomer, 2005; Rosenblatt, 2002).

En consecuencia, es fundamental que el alumno se dé cuenta que la literatura no está creada para espíritus dotados, y que por el contrario al estar inmerso en el texto se valida su propia experiencia y se propicia una dinámica que lo interpela, le devela un sentido, le produce un impacto y desarrolla su capacidad de sentir, de responder imaginativamente a los pensamientos y a la conducta de otros (Rosenblatt, 2002).

Lo cierto es que el desarrollo humano y el crecimiento personal son la esencia misma de la literatura, por lo tanto, cualquier proceso de condicionamiento cultural es visto en acción en las imágenes de la vida que un autor pone en un escrito. Así pues, la intervención, la mediación, la estrategia y el enamoramiento se producen desde la base de la experiencia vital, en donde las herramientas y los instrumentos se proporcionan para sopesar las diversas imágenes de la vida (Rosenblatt, 2002).

El enamoramiento, el despertar, es hoy responsabilidad de la escuela, y la escuela estableció al mediador en la figura del profesor. Si el profesor de literatura está atento a propiciar espacios para soñar, imaginar, crear, descubrir, escuchar, divertir y jugar, estará alimentando y liberando el espíritu creador de sus estudiantes. Es por ello que, el maestro debe ser un provocador permanente que planea procesos de lectura que impliquen la argumentación y la crítica, de manera que permita al estudiante ejercer su creatividad, argumentación, interpretación y producción.

De otra parte, retomando las palabras de Rincón (2003), la agudeza del mediador hace que los estudiantes busquen repre- sentaciones sociales con las que se identifican y suscitan emociones, sentimientos, hábitos $\mathrm{y}$ valores, que articulan el lazo entre la interpretación de las imágenes (si las hay) y los comportamientos y actitudes de los lectores.

Esta experiencia conjunta que el profesor hace con sus estudiantes cultiva el trabajo en grupo, porque los estudiantes no pueden solos, necesitan de la presencia permanente y activa del maestro para aportar a la comprensión del texto para discernir y extraer críticamente las visiones propias de la naturaleza humana que están encarnadas en los personajes literarios. El profesor de literatura es quien sugiere, motiva, busca, explora, conoce y discierne con el estudiante sobre los gustos literarios y necesidades de los estudiantes como nuevos lectores. Debe identificar quién es su discente y qué necesita este para iniciar su proceso lector que le ayude a comprenderse y comprender la humanidad.

Complementando estas ideas, Rosenblatt (2002) señala que el profesor es el principal apoyo para que los estudiantes conozcan lo literario, se familiaricen con la historia de la literatura, tengan una idea de las formas literarias, entiendan lo que leen, $\mathrm{y}$ consoliden cierto grado de discriminación crítica, pues es el profesor el que encauza al estudiante para que cree y confi- 
gure distintos sentidos (Fernández, Núñez Delgado \& Romero López, 2010). No obstante, el sentido no es perceptible para los otros, sino exclusivamente para el yo, que se fragmenta en palabra, en oración, en verso y en idea. Es por ello que, el texto dentro de sí sale como un tejido de palabras, de imágenes canónicas que parafrasean su yo contenido y su yo contexto en palabras.

Una tercera fase consistió en la implementación de prácticas de promoción y animación de la lectura literaria, adaptadas al contexto escolar. Esta fase se desarrolló en tres momentos. Primer momento: sensibilización literaria, se llevaron textos de Literatura Infantil y Juvenil (LIJ) a la clase, ya que su estructura es básica o primaria: inicio, nudo y desenlace, a la vez la trama de estos libros es sencilla, más fácil de entender y las historias son muy cercanas a la vida real de los estudiantes. De acuerdo con Rosenblatt (2002), "El adolescente, igual que el lector principiante, necesita encontrarse con una literatura para la cual posea el equipo intelectual y emocional, y cuente con la experiencia suficiente. También él debe recurrir a su experiencia pasada con la vida y con el lenguaje [...]" (p. 52). Con estos libros se realizó lectura en voz alta, lectura predictiva, lectura de imágenes y desarrollo de secuencias didácticas para explorar el libro.
En el segundo momento, se inició la lectura heterónoma y la lectura autónoma. La mayoría de los estudiantes escogieron libremente un libro de LIJ (utilizados en el primer momento). Un solo grupo decidió leer un libro que no estaba dentro de los que se llevaron a clase, Drácula de Bram Stoker. Luego, los discentes los leyeron en forma completa, analizaron brevemente, realizaron y presentaron en clase secuencias didácticas para abordar de una manera diferente y lúdica cada libro.

En el tercer momento, se realizó el Festival Silvinista de la lectura literaria (FESLELIT), los estudiantes construyeron 36 stands literarios para presentar como padrinos lectores, de una manera muy creativa y llamativa, el libro que leyeron. Después del FESLELIT, se invitó a los estudiantes a escoger voluntariamente otro libro de literatura para leer, y en clase, por medio de una instalación literaria, se dio a conocer este segundo libro que a su vez se reseñó para publicar en el muro de Silvinito Lector. Finalmente, se invitó a leer Juanantonio de la escritora Nana Rodríguez. Con gran sorpresa, 100 estudiantes compraron el libro por decisión propia, algunos de los capítulos se leyeron en clase y se planteó el diálogo - socialización literaria realizando análisis semióticos y reflexiones profundas; al mismo tiempo, se incursionó con la lectura en familia y en el ejerci- cio de escritura crítica.

\section{Los hallazgos}

Las categorías de análisis identificadas en el diagnóstico que sirven para acercarnos a resultados más concretos están inmersas, según Strauss y Corbin (2012), dentro del proceso de análisis de datos cualitativos que consideran pertinente el uso de la codificación abierta y la codificación axial. La codificación abierta es el proceso analítico por medio del cual se identifican los conceptos y se descubren los datos en sus propiedades. Para este caso en particular, las categorías son conceptos que representan fenómenos. Durante la codificación abierta, los datos se descomponen en partes discretas, se examinan minuciosamente y se comparan en busca de similitudes y diferencias. Los acontecimientos, sucesos, acciones o interacciones que se consideren relacionados, se agrupan en conceptos un poco más abstractos, denominados categorías. El nombre de estas categorías es gráfico y responde a aquello que evoca el investigador como referente de la información encontrada en los instrumentos utilizados en la investigación.

Hábito lector y mediación. Los jóvenes lectores fortalecieron el comportamiento lector gracias a la mediación que se realizó por medio de las estrategias para la iniciación literaria. Según Co- 
lomer (2005), “Aquí resulta útil pensar en la educación literaria como un aprendizaje de recorridos e itinerarios de tipo y valor muy variable. La tarea de la escuela es mostrar las puertas de acceso. La decisión de cruzarlas en distinta medida depende de los individuos" (p. 92).

En la Institución Educativa se dinamizó el proceso de lectura literaria en todos los estamentos, se generó interés, placer por la lectura de una manera diferente, llamativa, agradable y muy enriquecedora con la organización y puesta en acción de jornadas de lectura en voz alta y Festival Silvinista de la lectura literaria. Al respecto, Rosenblatt (2002) señala que: "La labor del maestro de literatura es propiciar interacciones fructíferas -o, más precisamente, transacciones- entre los lectores individuales y las obras literarias individuales" (pp. 52-53).

El texto literario se percibe, se imagina, se olfatea, en todos los entornos y más en los contextos libres, y no en aquellos institucionalizados o controlados. La inducción al texto literario se sacó de lo normativo y esto seguramente indujo otro tipo de acercamiento. El festival de la lectura literaria, el Silvinito lector o el muro literario, despertaron la creatividad y la diversidad en la presentación de los textos. El suprimir los complementos escolares normativos (clase, evaluación, notas, asistencia...) sugirieron un tipo de acercamiento más pausado, versátil, lúdico, y con actitudes de enamoramiento que complementó una figura didáctica como los anzuelos literarios, que cautivaron a varios participantes de la clase. Al parecer, estas nuevas formas de presentación del texto indujeron la sensibilidad para prefigurar y figurar el pensamiento. Los esquemas, los dibujos, las gráficas, las carteleras, las caracterizaciones y lo teatral, reportaron no solo diversidad en la presentación de los textos, sino que permitieron afinar la sensibilidad con respecto al texto literario como tal. Hubo un perspicaz olvido de lo fragmentario y una ilusión por saber del texto, en razón a la consecuencia de su presentación. Era seguramente necesario saber algo más del texto, porque pesaba la crítica de sus compañeros, el concepto respecto de su conocimiento, la valoración de sus expectativas y el autoconcepto de sus perspectivas humano-sociales.

En este mismo sentido, algunas de estas experiencias se realizaron dentro del aula de clase, pero teniendo en cuenta un poco la premisa de "el estudiante no debe salir del agua como entró". Para autodeterminar que la sesión tenía que ser tan enriquecedora que transformara y en varias ocasiones así sucedió. Con palabras de los estudiantes:
Leo más porque al principio era un fastidio para mí que leer un libro ahora me parece divertido y leo libros sin que me manden. / Creo que leo más, es hermoso tener sentimientos en nuestras manos por medio de un libro, tal vez muchas veces el libro puede ser nuestro espejo. Cada vez que leo un libro encuentro lo más interesante je, je. / Me encanta buscar más allá de las letras imaginarme la historia, sentir esas palabras. I Sí leo más, porque a mí no me gustaba leer, no porque no supiera sino porque me daba pereza, pero ahora me gusta porque me centro en la lectura y me relaciono con ella.

Actitud frente a la literatura.

En cuanto a la actitud frente a la Literatura, el estudiante-lector logró permear, participar, vivir el texto literario; especialmente los textos de Literatura Infantil y Juvenil, a la vez se preparó para leer obras estéticas más complejas porque la mirada que tenía hacia la lectura de textos estéticos había cambiado, y se había dado cuenta que sí era posible leer y disfrutar de la lectura en la escuela, aspecto que se vio reflejado en la compra de libros por propio interés, así como en los espacios que los mismos estudiantes abrieron para dialogar sobre libros de literatura que leían, por lo general, en los pa- 
sillos del colegio, a la hora del descanso. En este sentido, como lo plantea Rosenblatt (2002),

La participación personal del joven lector en una obra generará mayor sensibilidad a sus imágenes, estilo y estructura; esto, a su vez, reforzará su comprensión de las implicaciones humanas y la sofisticación literaria se sostienen y se nutren mutuamente. Ambos tipos de crecimiento son esenciales para que el alumno llegue a desarrollar la penetración y la habilidad requeridas para participar en obras literarias cada vez más complejas y significativas (p. 79).

Al respecto, los estudiantes expresaron:

Los libros son como un imán mientras más lee uno más quiere saber y estas actividades son como imanes atraen la atención de los estudiantes y estos empiezan a investigar hasta empezar a ser un lector frecuente / Si leo, porque descubri que la lectura no es aburrida / Me gusta aprender y conocer historias y más porque conozco gente que lee mucho $y$ cuando hablan de libros me sentía ignorante / He aprendido lo importante que es leer / Pues, leo un poco más y me intereso más / El año pasado no leí ningún libro este año lei cinco y pues fue algo muy bonito.

Complementa Rosenblatt (2002), la importancia de que el joven lector asuma una actitud espontánea frente al texto literario, lo que implica que en la escuela se debe dejar de insistir en los resúmenes o paráfrasis de las obras. A la vez, los docentes deben generar espacios favorables para que la literatura sea una experiencia vital y enriquecedora en el contexto académico de los estudiantes que posibilite un libre acercamiento al texto para leerlo y disfrutarlo.

Los espacios creados dentro y fuera del aula propiciaron que el estudiante fuera libre para leer, opinar y crear en torno a la literatura, en este caso específico la Literatura Infantil y Juvenil (LIJ). Por lo tanto, "el joven lector tiene que sentirse libre de dejar que su comentario adopte la forma dictada por lo que ha vivido mientras leía el libro" (Rosenblatt, 2002, p. 92). En consecuencia, las opiniones $\mathrm{y}$ actitudes del estudiante frente a la lectura con este ejercicio fueron genuinas.

Intereses Juveniles. Por medio de esta propuesta, también se logró que el lector-adolescente creara un vivir a través de la lectura literaria. Esto fue una transacción entre el lector y el texto en donde emergieron los recuerdos, las experiencias, los gustos, los vacíos y la personalidad del lector con la historia y con el personaje; en fin, con el texto mismo. Por lo tanto, se enfatiza en que la experiencia de leer no solo depende del texto sino del lector mismo, de su disposición, de sus sentimientos y de su entrega. Se puede inferir, por lo tanto, que la literatura transformó de alguna manera a los estudiantes-lectores. Como dice Rosenblatt (2002),

La experiencia literaria ha sido expresada como una transacción entre el lector y el texto del autor. Mas aún, tal como ocurre en la actividad creativa del artista, habrá factores selectivos que moldean la respuesta del lector. Este llega al libro desde la vida. Se aleja por un momento, de su preocupación directa con los diversos problemas y satisfacciones de su propia vida. Cuando cierre el libro volverá a pensar en ellos. (p. 62).

Una vez los estudiantes seleccionaron y leyeron libremente el texto literario, se identificó que ellos se interesaban por los siguientes temas: amor, aventuras, terror, realidad, violencia, vida cotidiana, vampiros, elfos, brujas, fantasía y ficción, entre otros. Respecto a esto, Petit (2008) afirma que "los lectores vamos a la ficción para intentar comprendernos, para conocer 
algo más acerca de nuestras contradicciones, miserias y grandezas, es decir acerca de lo más profundamente humano" (p. 38).

En esta lista de intereses, se encuentra una gran conexión con el cine y la literatura romántica. Se puede observar que los estudiantes tienen gran gusto por los héroes y por la mitología. Las sagas de Crepúsculo, Juegos del hambre, El señor de los anillos tienen personajes de acción que tienen que resolver problemas externos, en algunos de los personajes se presentan desafíos internos de "qué tanto soy capaz de...". Estos textos están muy conectados con la mitología, relatos fantásticos que hablan del honor de la heroicidad, de lo monstruoso, de vampiros, heroico desde lo oscuro, del amor, el terror, que son imaginación pura, creatividad pura, que está reflejando verdades profundas del ser humano como: la honestidad, la fidelidad, el amor verdadero, la justicia social. Los jóvenes-lectores, sin duda, apropiaron esta clase de literatura de una manera directa, debido a que su forma de entender es diferente, trascendental y más libre. Continuando con Rosenblatt (2002), la literatura es un camino para que el joven lector se comprenda a sí mismo y aprenda sobre la gente.

De igual manera, por medio de la literatura, el joven puede disfrutar plenamente del mundo que le rodea y a su vez significarse en él, descubriendo paso a paso su propia voz, motivo por el cual, empieza a tener un verdadero agenciamiento en el discurso no solo académico sino también personal. Así como lo afirma Rosenblatt (2002), "Cuando el alumno se ha conmovido por una obra literaria, se verá llevado a reflexionar sobre cuestiones del bien o el mal, de cualidades admirables o antisociales, de acciones justificables o injustificables" (p. 42).

Con palabras de los mismos estudiantes-lectores:

Me gusta Crepúsculo porque en primer lugar ya habia visto la película y me parecía interesante conocer el libro para ver en que se diferenciaba de la película. Además de la acción y el misterio me gusta la historia de amor. El amor prohibido que hay entre un vampiro y una humana, bueno esa restricción también existe en la realidad si uno lo analiza desde otro punto de vista. Uno de los propósitos del libro es querer afirmar que sí existe el amor verdadero sin importar la edad, $n i$ la condición social y que ese amor puede vencer todos los obstáculos que se presentan por el camino. También me gusta la participación de humanos, hombres lobos y vampi- ros que con sus poderes sobrenaturales protegen a la protagonista. En cuanto a la escritura me gustó que fuera detallada y minuciosa de los hechos. I Me gustan Los juegos del hambre, es una trilogía enfocada a la crítica social, la división de clases y la pobreza. Cuando lo lei me conmovió muchísimo como tenían que vivir aquellas personas y lo que tuvieron que hacer para sobrevivir. El libro nos enseña a querer más las cosas y valorarlas, también me hizo reflexionar sobre la comida y como a veces la desperdiciamos cuando otros la necesitan. Otra temática del libro es igualmente el amor y cómo es la fuerza más grande para derribar la opresión. En el libro se presenta un choque cultural porque vemos dos polos opuestos entre el capitolio (el gobierno) $y$ los distritos (pueblo). La opresión del capitolio sobre los distritos por medio de los juegos, para divertir la clase social más alta con el sufrimiento y muerte de los débiles (pueblo). Esto hace que los distritos decidan crear una resistencia y atacar al gobierno. Me gustan los libros que estén basados en hechos reales porque no me aburro. 
Acceso a la literatura. Se pudo encontrar que el estudiante comenzó a experimentar cambios como: comprar libros de literatura por interés propio; recomendar textos literarios, comentar e invitar a leer libros de literatura y aumentar el tiempo de lectura. Otra parte de la población se inclinó por buscar y leer los libros que les interesaba en internet (PDF) como, por ejemplo: Bajo la misma estrella de John Green, y La cabaña de William Paul Young. Estos títulos son cercanos a los estudiantes, porque ya han visto la película en el caso de Bajo la misma estrella y por referencias familiares en el caso de $\mathrm{La} \mathrm{Ca}$ baña.

\section{Conclusiones}

Sin lugar a dudas, el diálogo, la interacción y el discernimiento, pero ante todo el respeto a la diferencia, propician la aceptación de los demás y a la vez el autoconocimiento. Por consiguiente, al permitir el ingreso de la literatura a las aulas se establece una variedad de posibilidades que dan espacio al sueño, a la creación y, por lo tanto, al desarrollo de la empatía y el altruismo, al integrar con este espacio todas las circunstancias y factores de la vida, para configurar un mejor desarrollo humano $\mathrm{y}$, por lo tanto, un adecuado tejido social.

El papel de los mediadores se establece como crucial debido a que propicia anhelo e ilusión y genera, en muchas ocasiones, motivación y amor por lo literario. El mediador autoriza, legitima y proyecta. Para este caso en particular, la mejor mediación estuvo a cargo de los pares, quienes instruían y permeaban un mundo que en apariencia era distinto, pero que reflejaba, de alguna manera, su propia realidad.

En este sentido, se puede señalar que las estrategias para el enamoramiento del texto literario requieren de -el inducir-, -el llevar a-, el suscitar movilidad y propiciar una dinámica propicia en tres dimensiones esenciales: diversificar los contextos de aprendizaje, integrar la lectura a los propios intereses del estudiante e implementar estrategias de tipo convencional y no convencional. En esta dirección, Rosenblatt plantea que "La literatura proporciona un vivir a través de, no simplemente un conocer sobre: no el hecho de que los amantes murieron jóvenes y bellos, sino un vivir a través de Romeo y Julieta" (p. 65).

Los resultados de este trabajo ponen de manifiesto que las prácticas motivadas para la lectura propician en los estudiantes el interés para interpretar y cuestionar los contenidos leídos y para aventurarse a escribir acerca de temas cotidianos con una perspectiva crítica, en la que se comparte y expresan sentimientos, intereses y pensamientos acerca del mundo actual, su contexto sociocultural y sus problemáticas.

Vale la pena aclarar que, ni los estudiantes ni los docentes conocían las estrategias propuestas, de tal manera que cuando se familiarizaron y descubrieron que la riqueza de la lectura no se encontraba en el texto sino que emergía de la conexión del lector con el relato, las obras propuestas empezaron a cobrar vida desde sus propias vivencias y aparecieron las inferencias, los juicios valorativos, la comprensión de aspectos locales y globales, así como en algunos casos, un nivel crítico desde las relaciones intertextuales.

La educación puede mejorar su calidad si se logra un mayor y mejor acceso al lenguaje escrito, puesto que leer y escribir son herramientas cognitivas fundamentales para acceder al conocimiento, a la comprensión de las relaciones existentes entre el mundo natural y social, y son elementos sustanciales para la construcción de una identidad y para el ejercicio de las capacidades como analizar, comprender y argumentar (Rincón, 2003, p.127). 


\section{la palabra}

\section{Referencias}

Altamirano, F. (2012). El contagio de la literatura: otra mirada de la didáctica de la literatura. La Palabra, (21), 21-32. Tunja: UPTC.

Altamirano, F. (2016). Didáctica de la literatura: ¿Cómo se contagia la literatura? La Palabra, (28), 155171. Tunja: UPTC.

Brunner, J. (1986). Realidad mental y mundos posibles. Los actos que dan sentido a la experiencia. Madrid: Gedisa.

Borrero, J. (2012). Muchacha no vayas al bosque: orientaciones para una literatura en el campo expandido. La Palabra, (20), 49-67. Tunja: UPTC.

Cervera, J. (1989). En torno a la literatura Infantil. CAUCE, Revista de Filología y su didáctica, (12), 157-168. Valencia: Universidad de Valencia.

Colomer, T. (2005). Andar entre libros. México: Fondo de Cultura Económica.

Chambers, A. (2013). El ambiente de la lectura. México: Fondo de Cultura Económica.

Hernández, J. P. (2004). Animación y promoción de la lectura: consideraciones y propuestas. ( $3^{\mathrm{a}}$ ed.). Antioquia: Comfenalco.

Fernández, E., Núñez Delgado, M., \& Romero López, A. (2010). Conocimiento del profesor universitario de lengua, literatura y su didáctica. Revista Internacional de Investigación en Educación, $4(2), 345-356$.

Flórez Davis, J. (2010). El placer de aprender. Revista Electrónica Educare, 14, 41-47.

Hauy, M. (2014). Lectura literaria. Aportes para una didáctica de la literatura. Revista Zona próxima, 20, 22-34.

Lince Capillo, R. (2013). La relación de poder entre el intérprete de la vida y su texto: la literatura como narración de experiencias históricas. Estudios Políticos, 30(9), 11-30.

Lerner, D. (2011). Leer y escribir en la escuela: lo real, lo posible, lo necesario. México: Fondo de Cultura Económica.

Merino Risopatron, C. (2011). Lectura literaria en la escuela. Revista Horizontes educacionales, 1(16), 49-61.

Mckee Irwin, R. (2013). El recurso literario latinoamericano en su contexto globalizado. Cuadernos de literatura, 34(17), 65-81. 
Osorio, L. B. (2010). La promoción de lectura en tiempos aciagos. Antioquia: Fondo Editorial Comfenalco

Petit, M. (2013). Nuevos acercamientos a los jóvenes y la lectura. México: Fondo de Cultura Económica.

Petit, M. (2009). El arte de la lectura en tiempos de crisis. México: Océano.

Rajagopalan, K. (2005). Language politics and the linguist. Revista Brasilera de Linguistica Aplicada, $1(5), 83-95$.

Rincón, C. (2003). La enseñanza de la lectura y la escritura en Colombia 1870-1936. Bogotá: Editorial U. F.J.C.

Robledo, B. (2010). El arte de la mediación espacios y estrategias para la promoción de la lectura. Bogotá: Grupo editorial Norma.

Robledo, B. (2013). Hitos de la literatura infantil y juvenil iberoamericana. Madrid: Fundación SM.

Rosenblatt, L. (2002). La literatura como exploración. México: Fondo de Cultura Económica.

Sanjuán, M. (2011). De la experiencia de la literatura a la educación literaria. Análisis de los componentes emocionales de la lectura literaria en la infancia y la adolescencia. Revista de Estudios sobre lectura, 7, 85-99.

Strauss, A., \& Corbin, J. (2012). Bases de la investigación cualitativa. Medellín: Imprenta Universidad de Antioquia.

Suárez Gómez, E. (2011). La literatura testimonial como representación de pasados violentos en México y Colombia, siguiendo el corte y guerra en el paraíso. Revista de Ciencias sociales de la universidad iberoamericana, 11, 57-82.

Vásquez, F. (1999). Didácticas de la literatura en la escuela. Bogotá: Universidad Javeriana. 